\title{
INTERVIEW WITH ROBERT JENSEN
}

\author{
Prepared By \\ Pooya Naderi and Christy Craig
}

"Dr. Robert Jensen is a Professor of Journalism and Director of the Senior Fellows Honors Program in the School of Communications at the University of Texas at Austin. His scholarly work has focused on pornography and the radical feminist critique of sexuality and men's violence, along with analysis of race through a critique of white privilege and institutionalized racism.'"Excerpt drawn from http://uts.cc.utexas.edu/ rjensen/index.html]

STAR: You state in the book "Getting Off: Pornography and the End of Masculinity" that the goal is not to reduce masculinity to a kinder, gentler form, but to eliminate it. What does this process look like both at the individual and institutional level? How do you go about eliminating masculinity?

Jensen: The abolitionist position on masculinity is, I think, an important corrective to the current cultural obsession with gender and sex. By abolitionist, we do not mean that the male and female bodies are identical; obviously there are differences between those two types of bodies. There is no doubt that the differences in reproductive organs and hormones probably give rise to some kind of intellectual, emotional and moral differences. That is certainly a plausible hypothesis. But in the culture today the assumption is that those physical differences dictate quite distinct differences in emotional, moral and intellectual matters. The abolitionist position is a corrective to that; it suggests that rather than assume that those physical differences give rise to other kinds of differences - which is a focus on difference- - why not look first at what makes biological males and females roughly the same. I think this is especially 
important in periods when cultures are obsessed with and assume that the differences are natured and within a patriarchal culture where the assumption of those differences inevitably leads to the reinforcement of a disparate power relationship. Now, how would one do that? The first step is simply to make the argument in a culture where it not only is not the norm, it seen as almost a lunatic idea. So, talking about it is the first step. Pointing out that biological males and females have much more common than they do difference is a step. Beyond that there are, obviously, some profound implications for child-rearing. The feminist movement made some of these arguments and it did affect the way people bring up children. It would have profound implications for the working world and assumptions about who is appropriate for this job or that job. The feminist movement has made some inroads there, incomplete although a good start. Really it is less about how do you change institutions or practices and more about how do you change the way people think? If people started thinking differently, the changes would emerge quite organically. So, if we didn't look at a male and female body and make assumptions about those moral, emotional and intellectual traits attached to the sex difference, then the practices that reinforce those differences would evaporate over time.

STAR: The last chapter of your book is called "Masculinity-What Can Men Do?" What can women do throughout this process as well-what is your approach for women who are working on challenging the way we see masculinity and femininity?

Jensen: Well, one of the lessons I took away from my early feminist training was that when there are systems that distribute power in unjust ways, people who are in the privileged position, who have access to unearned power, should not as the first step dictate either an analysis of that situation to people in the subordinated position nor make it their first task to make recommendations on what those people should do. In other words, when you're in a position of unearned privilege power, the first step is to understand that system and speak to others in that same position about our moral obligation to change the nature of the political system, to change that distribution of power. That said, it is relatively obvious that 
if men in patriarchy are going to deconstruct the ideology of masculinity, work toward changes in practices and institutions, it will have a dramatic effect on women. What complicates this so much in gender is that women are socialized into this same patriarchal system and often have quite strong attachments to it. So, unlike, for instance, being white in the civil rights movement, white people could contribute to a movement in which there was relative clarity within the black community about the goals. I'm not saying there was $100 \%$ unity in the black community, but you didn't for the most part have to ask the question did black people feel themselves to be fully human. That was a given. In gender, it's more complex because many women, especially conservative women, will articulate and express allegiance to certain patriarchal norms. You can see where it becomes very difficult for men then to inject themselves into conversations. What complicates it even further is that within feminism - especially over the last 20 years or so-there has been a development of such diverse positions within feminism that even as a man trying to ally oneself with a feminist movement, one can't assume anything. So, pornography, prostitution, issues where that's most obvious, there is a feminist critique of the sexual exploitation industries in which I'm rooted, but then there are many women who identify as feminist who celebrate those industries. What can women do? Women can do what they feel is most appropriate to undermine patriarchy. But, not even all women believe patriarchy is something to be undermined. In other words, I could talk for five more minutes to dodge the question and I'd still be saying that it's really not my place.

STAR: Are there any claims that could be made about the nature of the male human that would explain pornography consumption?

Jensen: The older I get, the more cautious I get about ascribing behavior patterns from a particular moment in a particular culture to human nature or, in this case, gendered nature. The reason for this is quite simple: human nature clearly exists, we are biological beings and we have an evolutionary history. To pretend there is nothing that emerges from that would be literally insane. Our psychological states, our moral development, our emotional make-up, they are all 
part of our nature and they have roots in our biology. To contest that would be nonsensical. What we also know is that human nature is widely variable. That is, each one of us have within us the potential to be both compassionate beings who act out of love and solidarity, we also have the capacity to be quite pathological and violent beings that act out of only self interest. Both things are part of our nature, so what is human nature? Human nature is this widely variable response to the conditions under which we live. I would focus on the conditions under which we live, trying to learn what we can along the way about what human nature is, but I do not think we have the intellectual tools to understand much or make definitive claims about human nature. In the application of that general rule to the study of pornography one often hears, for instance, that the reason men like pornographic movies more than women - the consumption of pornography is disproportionately male-is because men are more "visually cued"- that is the phrase that one hears. Well, what does this mean? I often ask mixed audiences, does this mean that women in the audience have no reaction to the physical appearance of a potential partner? Do women live on a higher plane of spirituality where physical appearances don't move them in any way? Everyone laughs because, of course, women are visually cued as well. What that is a way of saying is that men are socialized to objectify women and that is a very disturbing reality. To know that much of your socialization as a man has been to see women as not full human beings but as objects that exist, at least in part, for your sexual pleasure. To understand how that socialization process came to be is complex and to take it apart is even more complex. It is much easier and more reassuring to say that men are just more "visually cued" than women. To me, it is almost nonsensical. How would you test it in some way that was not culturally specific? Are men in the contemporary United States trained to see women as objects and hence do they tend to be more visually cued about sexuality. Sure. But all that says is that you live in patriarchy, in which women are devalued and objectified. I am not saying there are not potentially biological differences between male and female humans that might not lead to differences in attraction to sexually explicit material, maybe there are. But the idea that we can make 
these overarching statements based on virtually no evidence is pretty silly. Why not start with what we know, which is that men and women are socialized quite differently in patriarchy and that one of these sites of struggle is sexuality.

STAR: What was the process like to go through realizing your own role in the objectification of women, after you had started the study of pornography?

Jensen:Well, it was pretty unpleasant, remains unpleasant to this day. Which is just a way of saying that if you live in a system that distributes power and resources in profoundly unjust ways, any recognition and engagement with that is going to be unpleasant. Whether you're in the dominant position or the subordinated position. That is, it doesn't' feel good to recognize you're in a position in which you get a lot of things, not because you've earned them but because they come to you, and that in the process of growing up in such a society you're trained to view other people in ways that are inconsistent with your own basic principles. That's not fun. It is also not fun to be on the bottom of that hierarchy and realize you're being seen that way. So, it seems to me that anyone who takes seriously social inequality and injustice, and commits to trying to both deconstruct it and to try to change it, what you're signing up for is essentially a life of constant tension, struggle, stress, and misery! Okay, maybe not misery, but struggles. And there is built into it inevitable tension and stress, because what you do along the way is learn the unending lesson that there is a gap between who you believe yourself to be and who you really are. And that's never particularly fun. But it's also a part of the human condition if one wants to be a moral agent, is to recognize that the struggle is to see the ways in which you don't live up to your own stated principles. And for me, in a very visceral way, that happens still to this day. There have been more dramatic moments when I've had to recognize how deeply that socialization process has reached into me. In the beginning of the study of pornography, it was around a recognition of how much I routinely objectify women and see women that way. Whether or not I act on it, I can control, but the seeing is more difficult to control. I struggle with that all the time. 
I think in the book I mention a moment when, in doing a project with my friend Gail, it was particularly dramatic, because as we were watching these films, she was literally getting ill because she was identifying with the women and saying "Oh my God, what must it be like to feel what that woman is now going through." She was empathizing with the women. And when I was watching them I was becoming aroused and realized that I've been socialized to identify with the male and to see that as pleasurable even though the activity is undoubtedly causing discomfort for the woman. Well, that wasn't a fun weekend, for either one of us, for precisely the reasons I said. She had to recognize in one more way the degree to which she is identified in the culture as a thing to be fucked, and I had to recognize the degree to which I was socialized to see her as a thing to be fucked. One can control one's actions but still struggle with the process of seeing, and I think that's why it is so difficult, and I think that's why many men don't want to deal with it. I also think this is why so many white people don't want to recognize what it means to be white in this culture, because if you take that seriously, it's disturbing, and not in some psycho-babble kind of way. It shakes you to your core, it's not fun. But, that is the world we live in.

STAR: What lasting effect do you believe Andrea Dworkin's work can have and what you believe is essential for younger generation of feminists to know about her and her goals?

Jensen: Andrea Dworkin was a rare human being. She was a complex person. I did not know her personally, I only met her once, but I think I have read every word that has ever been published by her. Andrea is a special person for me because she is the doorway through which I entered this subject. Andrea's work had that power not just for me, but for many, many people. If you go back and read Andrea's work now, some of it feels very dated, which is to be expected since much of it was written thirty to forty years ago, but what endures is the power of the central message and a relentless engagement with the ugliness of the world created by patriarchy. What is so special about Andrea from my point of view is that she never looked away from that. She had an incredible courage to engage 
that. From my own observations of her career and from speaking with people that knew her much better than I, Andrea paid a price for that-you could see it in her body and you could hear it in her voice. In a lot of ways, I think, Andrea's unwillingness to look away is what killed her and what took her out of this world far too early. It is not easy to engage the horror of this world on a regular basis. People who have done it have often been shaken or shattered by it. For me, the incredible perception that Andrea had strengthened her analysis and the power of her writing, but it is also about the sacrifice she made. For instance, people who knew her tell stories of Andrea giving a speech on sexual violence, domestic violence, pornography, etc. After the talk, there would be a line of women who would come up and say to her, "I have never told anybody this, but. .." and share their stories. Andrea was a profoundly compassionate human being from the descriptions I know of her. She did not turn those women away, she listened. In a way, I think, Andrea literally took every one of those stories into her being. Most of us find ways to buffer, but Andrea never buffered. It is what made her writing and her speaking so brilliant and, I think, it is also what killed her. The way in which Andrea's work has been marginalized within academic feminism and erased from the Women's Studies canon is unfortunate. It fails to honor the brilliance of her analysis, but also the sacrifice of her being. When I survey a crowd of young women, including Women's Studies majors, not only have many of them not read her, most of them have never heard of her, and yet she is a founding mother of the Second Wave of Feminism. I still find myself getting very emotional just thinking about her. She was a powerful presence on this Earth for the years she was here.

STAR: One of the key critiques of your work is that you don't interview the women in pornography enough. Do you think it is necessary to engage the women in the sex industry more to take this work further or is that not as necessary as some of your critics believe?

Jensen: No, I think it is very necessary and I wish I had a way to have meaningful conversations with those women. But that is very difficult for pretty obvious reasons. One is the degree to which I 
was ever able to interview women in the industry especially at the annual industry convention. The interviews were fairly predictable. These are essentially public relations venues where people in the industry are working the crowd, whether it is working the journalists or the fans or other people in the industry. And that's not a place where you get meaningful reflections on the nature of the industry. So, if you interview women in pornography there, for the most part they tell you that they love their work, they feel empowered, they're financially successful - the things that you would expect. To get beyond that requires the establishment of some sort of trust and it is very difficult to create that. People in the industry are obviously skeptical about people from outside the industry. So, yes, I think it is important if one wants to understand the reality of those women's' lives, their contribution to that is central. On the other hand, it's not the case that they or any other group of people have an exclusive insight into the nature of their own work. We are all in some state of false consciousness, I mean, that's a phrase that is no longer sheik, but it is a very important phrase. I don't know of a single human being who can't look at some point in their life and recognize that the belief you had about your behavior at that point was, in fact, false consciousness. I can go back and look at many points in my life where I thought I was acting on a set of motivations and understandings, and looking back now I can see, no, I was deluding myself, I was actually acting from a different set of motivations. But I wasn't able to see them then. Take for example, teenagers who engage in self-destructive behavior. They will tell you at the time they're doing it, is because they're having fun. How much of it is rebellion against some authority such as a parent? Well, a lot of it is. So at that point those teenagers have false consciousness. They're acting on a set of motivations they do not understand. That is part of being human. So, we cannot pretend that the statements made by a person at a particular point in time are definitive - for us, for anyone else. In what I would call the sexual exploitation industries, the gap between the way women tend to describe their work when they are in that industry and the way they may describe their work when they are out of that industry can be quite different. In this case, there is a record of that gap, and so 
we have to look not only at what women say when they are in the industry but what they say when they are outside the industry. Just to give you an example, I have a friend who was at some point in her youth a stripper, around the college age and right after college. She says if you had asked me at the time what she was doing, she would have told you it was empowering and she was in charge of her own life and her sexuality, the list is pretty standard. She says that now, ten years later, she looks back and sees that she was emotionally a mess, she had not yet worked through her own history of sexual abuse as a child, she was drunk and drugged out most of the time, she was in a profoundly dissociated state through much of that performing. And so, what is the "truth?" The "truth" is a complex combination of all of these things. Yes, the voices of women are crucial, but the claim that one can take a set of voices from a particular industry at a particular time and proclaim them to be definitive of the experience is simply silly. That is what the supporters of pornography would like to do is to take a few high profile women who will make such claims and say there, that defines the experience. There are two questions. What about what those women might say ten years from now, twenty years from now? And by the way, if you go outside of that relatively narrow band of high profile, relatively successful women in the industry and look at the entire set of women who have performed in pornography over the last twelve months, what is the range of experience? Well, some of those women you'll never find, you'll never get to, you could never identify them. Some of them are dead. So, what's the "truth?" Those are the questions that come up. It is what makes research difficult both in obtaining those narratives and in understanding which narratives tell you the most about the nature of the industry. Any sociological research has the same problem. 